\title{
Mid-infrared fiber-coupled supercontinuum spectroscopic imaging using a tapered chalcogenide photonic crystal fiber
}

Petersen, Christian Rosenberg; Prtljaga, Nikola; Farries, Mark; Ward, Jon; Napier, Bruce; Lloyd, Gavin Rhys; Nallala, Jayakrupakar; Stone, Nick; Bang, Ole

\section{Published in:}

Proceedings of SPIE

Link to article, DOI:

$10.1117 / 12.2288541$

Publication date:

2018

Document Version

Publisher's PDF, also known as Version of record

Link back to DTU Orbit

Citation (APA):

Petersen, C. R., Prtljaga, N., Farries, M., Ward, J., Napier, B., Lloyd, G. R., Nallala, J., Stone, N., \& Bang, O.

(2018). Mid-infrared fiber-coupled supercontinuum spectroscopic imaging using a tapered chalcogenide photonic crystal fiber. In Proceedings of SPIE (Vol. 10489). [1048905] SPIE - International Society for Optical

Engineering. Proceedings of SPIE - The International Society for Optical Engineering

https://doi.org/10.1117/12.2288541

\section{General rights}

Copyright and moral rights for the publications made accessible in the public portal are retained by the authors and/or other copyright owners and it is a condition of accessing publications that users recognise and abide by the legal requirements associated with these rights.

- Users may download and print one copy of any publication from the public portal for the purpose of private study or research.

- You may not further distribute the material or use it for any profit-making activity or commercial gain

- You may freely distribute the URL identifying the publication in the public portal 


\section{Mid-infrared fiber-coupled supercontinuum spectroscopic imaging using a tapered chalcogenide photonic crystal fiber}

Christian Rosenberg Petersen, Nikola Prtljaga, Mark Farries, Jon Ward, Bruce Napier, et al.

Christian Rosenberg Petersen, Nikola Prtljaga, Mark Farries, Jon Ward, Bruce Napier, Gavin Rhys Lloyd, Jayakrupakar Nallala, Nick Stone, Ole Bang, "Mid-infrared fiber-coupled supercontinuum spectroscopic imaging using a tapered chalcogenide photonic crystal fiber," Proc. SPIE 10489, Optical Biopsy XVI: Toward Real-Time Spectroscopic Imaging and Diagnosis, 1048905 (19 February 2018); doi: 10.1117/12.2288541

SPIE. Event: SPIE BiOS, 2018, San Francisco, California, United States 
Invited Paper

\title{
Mid-infrared fiber-coupled supercontinuum spectroscopic imaging using a tapered chalcogenide photonic crystal fiber
}

\author{
Christian Rosenberg Petersen ${ }^{1, *}$, Nikola Prtljaga, ${ }^{2}$ Mark Farries, ${ }^{2}$ Jon Ward, ${ }^{2}$ Bruce Napier, ${ }^{3}$ \\ Gavin Rhys Lloyd, ${ }^{4}$ Jayakrupakar Nallala, ${ }^{5}$ Nick Stone ${ }^{5}$, Ole Bang, ${ }^{1,6}$ \\ ${ }^{I}$ DTU Fotonik, Technical University of Denmark, Ørsteds Plads bldg. 343, DK-2800 Kgs. Lyngby, Denmark. \\ ${ }^{2}$ Gooch \& Housego, Broomhill Way, Torquay TQ2 2QL, UK. \\ ${ }^{3}$ Vivid Components, Dr.-Rörig-Damm 22, 33102 Paderborn, Germany. \\ ${ }^{4}$ Biophotonics Research Unit, Gloucestershire Hospitals NHS Foundation Trust, Gloucester, GL1 3NN, UK. \\ ${ }^{5}$ Biomedical Physics, School of Physics and Astronomy, University of Exeter, Stocker Road, Exeter, EX4 4QL UK. \\ ${ }^{6}$ NKT Photonics A/S, Blokken 84, DK-3460 Birkerød, Denmark. \\ *chru@fotonik.dtu.dk
}

Keywords: Supercontinuum, spectroscopic imaging, mid-infrared, tissue imaging, chalcogenide optical fiber.

\begin{abstract}
We present the first demonstration of mid-infrared spectroscopic imaging of human tissue using a fiber-coupled supercontinuum source spanning from 2-7.5 $\mu \mathrm{m}$. The supercontinuum was generated in a tapered large mode area chalcogenide photonic crystal fiber in order to obtain broad bandwidth, high average power, and single-mode output for good imaging properties. Tissue imaging was demonstrated in transmission by raster scanning over a sub-mm region of paraffinized colon tissue on $\mathrm{CaF}_{2}$ substrate, and the signal was measured using a fiber-coupled grating spectrometer. This demonstration has shown that we can distinguish between epithelial and surrounding connective tissues within a paraffinized section of colon tissue by imaging at discrete wavelengths related to distinct chemical absorption features.
\end{abstract}

\section{INTRODUCTION}

Mid-infrared (mid-IR) spectroscopic imaging is a promising label-free technique with the potential for aiding researchers and clinicians in the study and diagnosis of cancer and other malignant diseases, but in order to transfer the technology from the lab and into the clinic it must be able to compete with conventional histopathology in terms of speed and reliability. Key to this is the development of compact, portable, turn-key systems relying on high brightness laser sources to provide a high signal-to-noise ratio for real-time measurements. In recent years, several demonstrations of mid-IR spectroscopic imaging using quantum cascade lasers (QCL) [1,2] has emerged resulting in a drastic reduction in acquisition time from hours to minutes, which makes it very attractive for clinical applications. However, only preliminary work has been performed with using supercontinuum (SC) sources for spectroscopic imaging in the mid-IR region [3-5]. The use of mid-IR supercontinuum sources for spectroscopic imaging has the potential for covering both the functional group region $(2.5-6.7 \mu \mathrm{m})$ and part of the fingerprint region $(6.7-15 \mu \mathrm{m})$ from a single compact source [6-9], that can be several orders of magnitude brighter than a synchrotron IR beamline [5] whilst being compatible with existing broadband technologies such as Fouriertransform infrared (FTIR) spectrometry and array detectors. This demonstration represents one of the first steps toward developing SC-based spectroscopic imaging in the mid-IR and is among

Optical Biopsy XVI: Toward Real-Time Spectroscopic Imaging and Diagnosis, edited by Robert R. Alfano, Stavros G. Demos Proc. of SPIE Vol. 10489, $1048905 \cdot$ - (c) 2018 SPIE - CCC code: 1605-7422/18/\$18 - doi: 10.1117/12.2288541 
several results of the European research project MINERVA: MId- to NEaR infrared spectroscopy for improVed medical diAgnostics, that was a collaboration between thirteen organizations from industry and academia across seven European nations with the goal of developing mid-IR technologies for high-volume pathology screening and in-vivo skin surface examination for the early diagnosis of cancer.

\section{FIBER-COUPLED SUPERCONTINUUM SOURCE}

The fiber-coupled SC source was based on a tapered large mode area chalcogenide $(\mathrm{ChG})$ photonic crystal fiber (PCF). The ChG PCF was fabricated from highly purified $\mathrm{Ge}_{10} \mathrm{As}_{22} \mathrm{Se}_{68}$ glass by SelenOptics using the preform casting method producing low-loss PCFs with a core/cladding diameter of $11.6 / 125 \mu \mathrm{m}$, hole diameter $\mathrm{d}=3.4 \pm 0.1 \mu \mathrm{m}$ and pitch $\Lambda=7.6 \pm 0.1 \mu \mathrm{m}$, resulting in $\mathrm{d} / \Lambda=0.45$. The large initial mode area allowed for high damage threshold and ease of coupling to the fiber, while the PCF structure enabled single-mode beam quality for diffraction-limited imaging. The taper was made post-drawing post-drawing using a filament-based tapering system operating at 258 ${ }^{\circ} \mathrm{C}$. The fiber was pulled with a translation speed of $3.8 \mathrm{~mm} / \mathrm{min}$, starting tensile strength of $40-50 \mathrm{~g}$, and $15 \mathrm{~g}$ in the waist section. The taper was translated with a speed of $4 \mathrm{~cm} / \mathrm{min}$ to obtain a $4 \mathrm{~cm}$ uniform waist section with $6.6 \mu \mathrm{m}$ core diameter. The transition regions measured $2 \mathrm{~cm}$ and $3 \mathrm{~cm}$ on the input and output side, respectively. A total fiber length of around $1 \mathrm{~m}$ was used for flexible beam delivery, and the fiber was subsequently end-capped, polished and fitted with FC connectors as seen in Fig. 1(a) for better environmental stability, robustness, and ease of coupling to the scanning system. After fabrication the transmission of the fiber cable was tested using a Fourier transform infrared (FTIR) spectrometer, which indicated guidance up to $10 \mu \mathrm{m}$ as seen in Fig. 1(b). The FTIR transmission spectrum also revealed several impurity absorption peaks from Se-H at $4.5 \mu \mathrm{m}, \mathrm{H}-\mathrm{O}-\mathrm{H}$ at $6.3 \mu \mathrm{m}$ and $\mathrm{Ge}-\mathrm{O}$ at $7.9 \mu \mathrm{m}$. The absorption features at $4.25 \mu \mathrm{m}$ and 5.5-7.5 $\mu \mathrm{m}$ was due to atmospheric absorption from $\mathrm{CO}_{2}$ and $\mathrm{H}_{2} \mathrm{O}$, respectively.

Broadband SC generation spanning 2-7.5 $\mu \mathrm{m}$ was achieved by pumping the ChG PCF with around $250 \mathrm{fs}$ pulses at $4.35 \mu \mathrm{m}$ (85 $\mathrm{nm}$ bandwidth) from a single-pass $\mathrm{MHz}$ optical parametric amplifier [6]. The pump wavelength was chosen to fit between the $\mathrm{CO}_{2}$ and $\mathrm{Se}-\mathrm{H}$ absorption features to reduce losses and avoid damage at the input. To reduce the intensity on the sample the spectrum was long-pass filtered at $4.5 \mu \mathrm{m}$ as shown in Fig. 1(c), resulting in around $9 \mathrm{~mW}$ of power delivered to the sample. At this power level no tissue damage was observed, and during the scan the laser exposure remained around 15 times below than the maximum permissible exposure (MPE) level recommended for skin in the IEC 60825-1:2014 international standard. The SC spectrum display clear signs of water absorption from 5.5-7.5 $\mu \mathrm{m}$ due to the atmosphere, and the sharp dip at $6.3 \mu \mathrm{m}$ coincide with the water impurity absorption in the $\mathrm{ChG}$ glass. Unlike previous experiments with similar tapered ChG PCFs reported in [6] the spectrum did not extend beyond $7.5 \mu \mathrm{m}$ due to a series of design compromises, such as a long uniform fiber length and a fiber geometry suitable for endcapping and connectorization. 
(a)
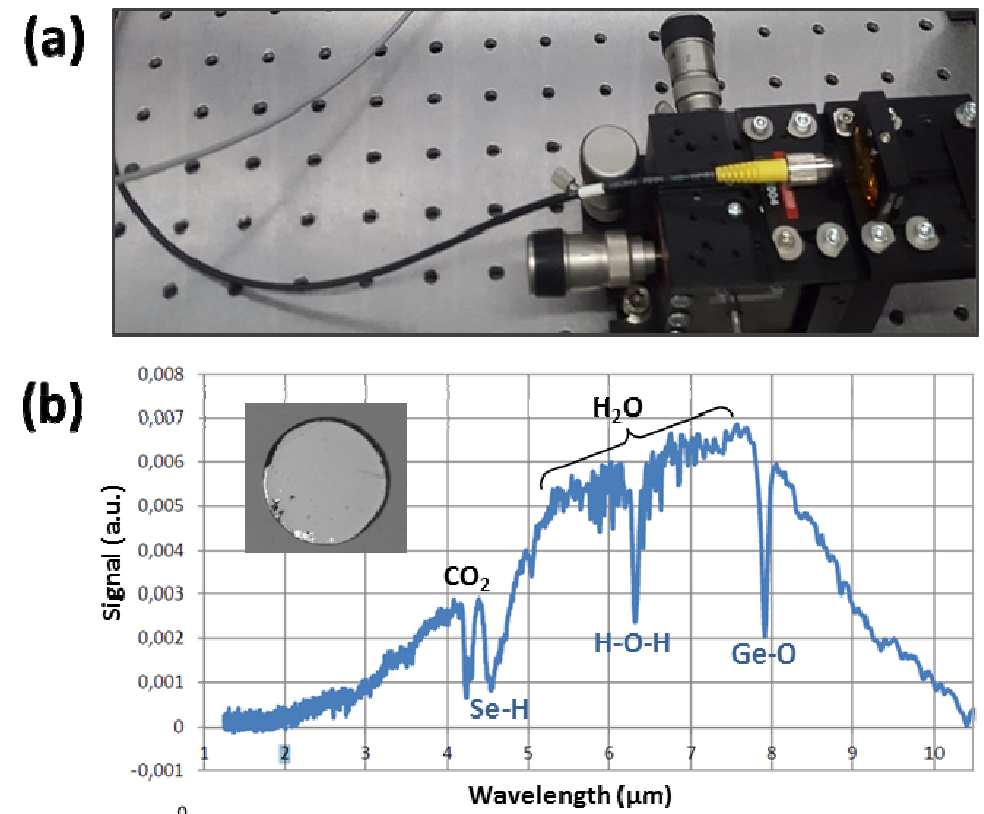

(c)

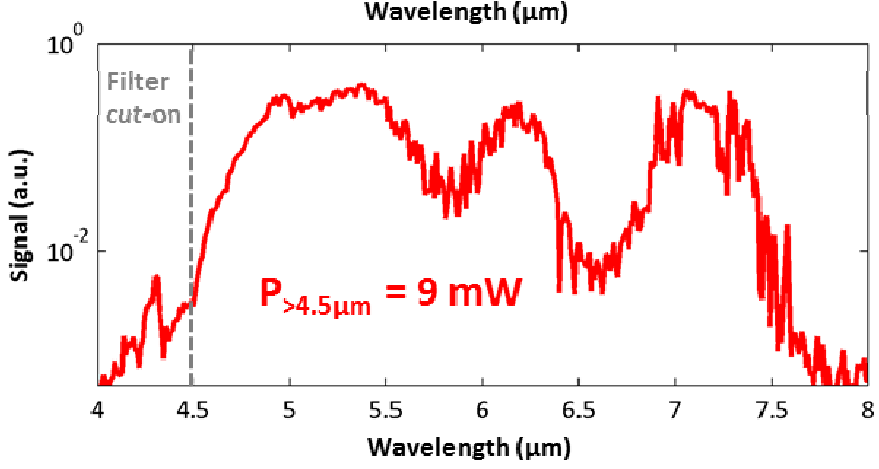

Figure 1. (a) Photograph of the tapered ChG PCF cable mounted on a translation stage for pump laser coupling. The white tape indicates the start of the tapered region. (b) FTIR transmission test demonstrating guidance up to $10 \mu \mathrm{m}$ with various absorption features from the fiber (Se-H, H-O-H, Ge-H) and surrounding atmosphere $\left(\mathrm{CO}_{2}, \mathrm{H}_{2} \mathrm{O}\right)$. The insert shows a microscope image of the polished end-cap on the input side of the fiber cable. (c) Spectrum of the filtered SC used for imaging.

\section{SAMPLE PREPARATION}

The sample was a non-tumoral colon tissue section obtained from the Gloucestershire Royal Hospital with the approval of the local research ethics committee. Two tissue sections where cut from this block, where the first $3 \mu \mathrm{m}$ section was used for standard haematoxylin and eosin (H\&E) staining on a glass slide for confocal microscopic examination and a second adjacent $7 \mu \mathrm{m}$ thick section was mounted on a calcium fluoride $\left(\mathrm{CaF}_{2}\right)$ substrate for mid-IR imaging. Figure 2 shows a confocal image of the H\&E stained tissue section, in which the various histological regions are clearly distinguished. The main objects of interest are the circular structures - the colonic crypts which consist of a darkly stained outer layer (nuclear region) and a lightly stained interior (cytoplasmic region). 


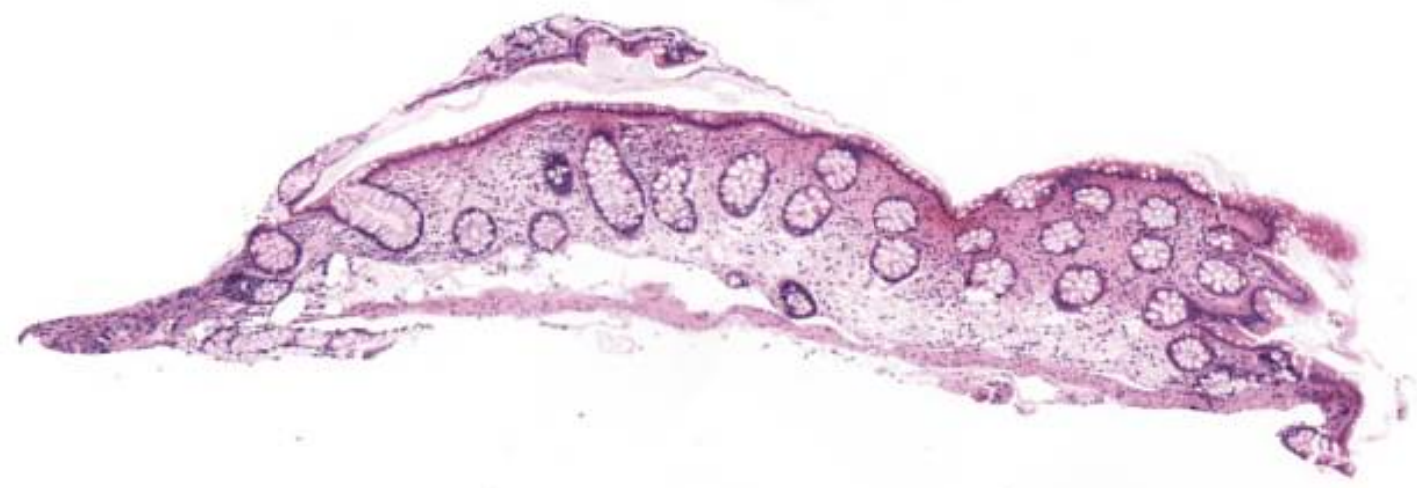

Figure 2. Confocal microscope reflection image of the $3 \mu \mathrm{m}$ thick H\&E stained colon tissue section.

\section{SPECTROSCOPIC IMAGING SYSTEM AND RESULTS}

Figure 3 shows the scanning system used for spectroscopic imaging.

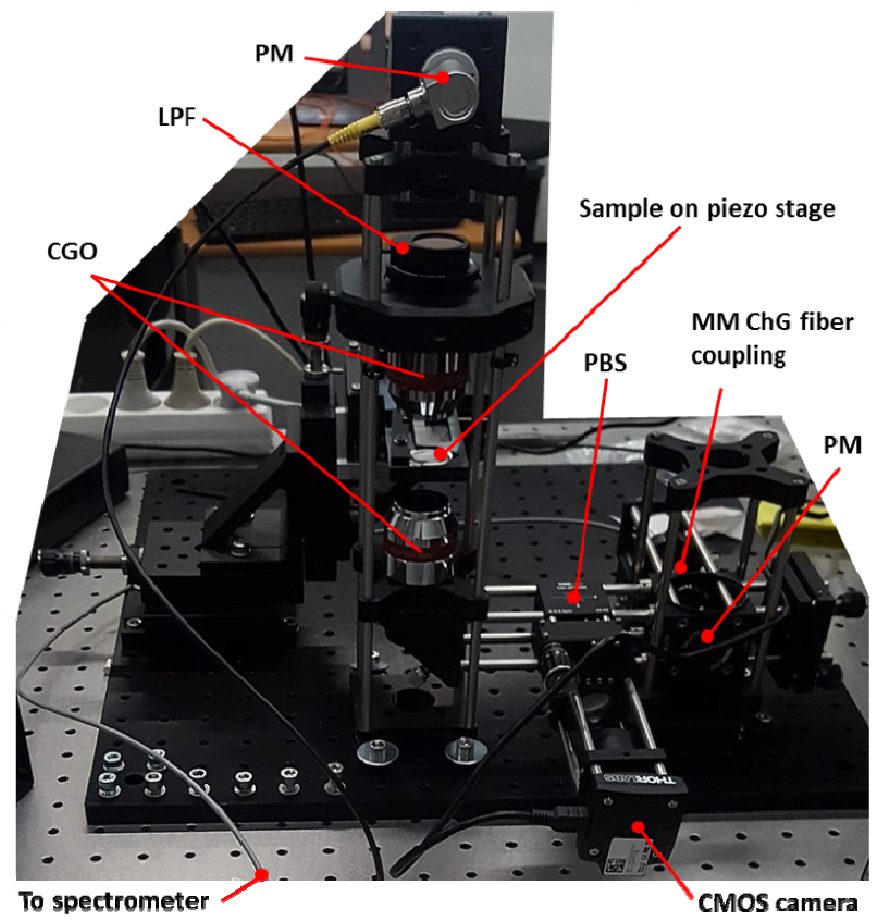

Figure 3. Fiber-coupled scanning system for spectroscopic imaging. PM: Parabolic mirror, LPF: Long-pass filter, CGO: Cassegrain objective, PBS: Pellicle beam splitter.

The system is fiber coupled and has a multimode fiber output for the spectrometer enabled by FC/PC parabolic mirror collimators. The system employed a pair of $15 \mathrm{x}$ reflective Cassegrain objectives for achromatic diffraction-limited imaging, as well as a CMOS camera for visual alignment of the sample. The $\mathrm{CaF}_{2}$ sample plate was mounted on a piezo-stage and tissue imaging was demonstrated by raster in $5 \mu \mathrm{m}$ steps over a $600 \times 600 \mu \mathrm{m}$ region of the sample. The signal was measured in transmission using a fiber-coupled grating spectrometer and MCT detector in combination with lock- 
in amplification. The signal was chopped at $4 \mathrm{kHz}$ in order to use lock-in detection, and a $50 \mathrm{~ms}$ time constant was needed for maximum dynamic range due to significant loss in the beam-splitter and fiber-coupling to the spectrometer. The acquisition rate was further limited to $100 \mathrm{~ms}$ in order to avoid motion artifacts, which resulted in a 24 minute acquisition time for a single-wavelength pointscan image. However, this was a first proof-of-principle demonstration, and the acquisition rate can easily be improved by using a camera or array detector in combination with acousto-optic- or linear variable filters. Figure 4(a-d) show a comparison between the H\&E stained tissue section and the mid-IR sample visualized using the CMOS camera, SC source and a state-of-the-art FTIR focalplane array system, respectively. The SC and FTIR images are captured at $6.45 \mu \mathrm{m}$ where the SC is low; however, it is still possible to distinguish between epithelial and surrounding connective tissues, and with further improvements to the technology we expect to be able to obtain high quality images within few seconds, similar to what was demonstrated at shorter wavelengths in [1].
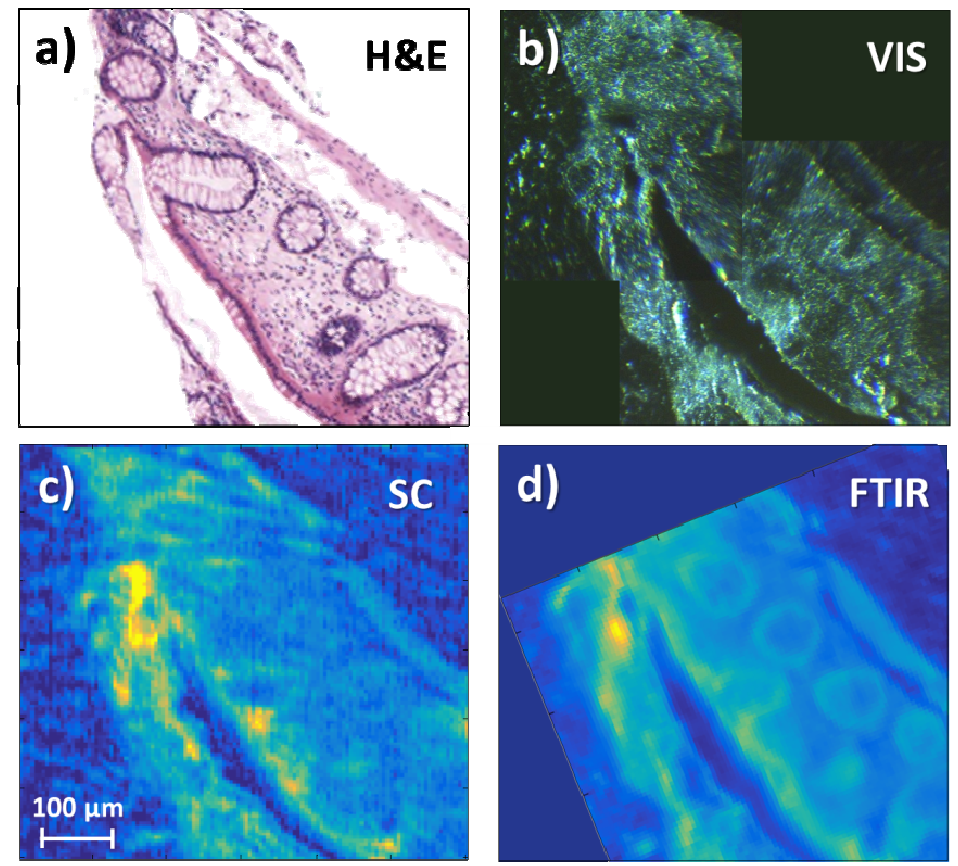

Figure 4. Comparison between (a) H\&E stained tissue section, and (b,c,d) mid-IR sample visualized using the CMOS camera (b), SC source (c) and FT-IR focal-plane array system (d).

\section{CONCLUSION}

In conclusion, we have demonstrated the feasibility of using a broadband fiber-coupled mid-IR SC source in combination with a scanning system for spectroscopic imaging of tissue.

\section{ACKNOWLEDGEMENTS}

This work was supported by the European Commission through the Framework Seven project MINERVA: MId- to NEaR infrared spectroscopy for improVed medical diAgnostics (FP7-ICT 317803; www.minerva-project.eu). The authors further acknowledge Laurent Brilland of SelenOptics and Johann Troles of Rennes University for the fabrication and characterization of the 


\section{REFERENCES}

1. K. Yeh, S. Kenkel, J.-N. Liu, and R. Bhargava, "Fast Infrared Chemical Imaging with a Quantum Cascade Laser," Anal. Chem. 87, 485-493 (2015).

2. M. J. Pilling, A. Henderson, B. Bird, M. D. Brown, N. W. Clarke, and P. Gardner, "Highthroughput quantum cascade laser (QCL) spectral histopathology: a practical approach towards clinical translation," Faraday Discuss 187, 135-154 (2016).

3. M. Farries, J. Ward, I. Lindsay, J. Nallala, and P. Moselund, "Fast hyper-spectral imaging of cytological samples in the mid-infrared wavelength region," in Proc. of SPIE 10060 (2017), p. 100600Y.

4. S. Dupont, C. Petersen, J. Thøgersen, C. Agger, O. Bang, and S. R. Keiding, "IR microscopy utilizing intense supercontinuum light source," Opt. Express 20, 4887-4892 (2012).

5. I. D. Lindsay, S. Valle, J. Ward, G. Stevens, M. Farries, L. Huot, C. Brooks, P. M. Moselund, R. M. Vinella, M. Abdalla, D. de Gaspari, R. M. von Wurtemberg, S. Smuk, H. Martijn, J. Nallala, N. Stone, C. Barta, R. Hasal, U. Moller, O. Bang, S. Sujecki, and A. Seddon, "Towards supercontinuum-driven hyperspectral microscopy in the mid-infrared," in Proc. of SPIE 9703 (2016), Vol. 2016, p. 970304.

6. C. R. Petersen, R. D. Engelsholm, C. Markos, L. Brilland, C. Caillaud, J. Trolès, and O. Bang, "Increased mid-infrared supercontinuum bandwidth and average power by tapering large-modearea chalcogenide photonic crystal fibers," Opt. Express 25, 15336-15347 (2017).

7. D. D. Hudson, S. Antipov, L. Li, I. Alamgir, T. Hu, M. E. Amraoui, Y. Messaddeq, M. Rochette, S. D. Jackson, and A. Fuerbach, "Toward all-fiber supercontinuum spanning the midinfrared," Optica 4, 1163-1166 (2017).

8. C. R. Petersen, U. Møller, I. Kubat, B. Zhou, S. Dupont, J. Ramsay, T. Benson, S. Sujecki, N. Abdel-Moneim, Z. Tang, D. Furniss, A. Seddon, and O. Bang, "Mid-infrared supercontinuum covering the 1.4-13.3 $\mu \mathrm{m}$ molecular fingerprint region using ultra-high NA chalcogenide stepindex fibre," Nat. Photonics 8, 830-834 (2014).

9. T. Cheng, K. Nagasaka, T. H. Tuan, X. Xue, M. Matsumoto, H. Tezuka, T. Suzuki, and Y. Ohishi, "Mid-infrared supercontinuum generation spanning 2.0 to $15.1 \mu \mathrm{m}$ in a chalcogenide step-index fiber," Opt. Lett. 41, 2117-2120 (2016). 